\title{
Influence of harvest date on volatile and sensory profile of vine leaves infusions from two Portuguese red grape varieties
}

\author{
António M. Jordão ${ }^{1, a}$, Ana C. Correia ${ }^{1}$, Fernando M. Nunes ${ }^{2}$, and Fernanda Cosme ${ }^{3}$ \\ ${ }^{1}$ Polytechnic Institute of Viseu (CI\&DETS), Agrarian Higher School, Estrada de Nelas, Quinta da Alagoa, Ranhados, 3500-606 Viseu, \\ Portugal \\ ${ }^{2}$ CQ-VR, Chemistry Research Centre, University of Trás-os-Montes and Alto Douro, School of Life Science and Environment, \\ Chemistry Department, 5001-801 Vila Real, Portugal \\ ${ }^{3}$ CQ-VR, Chemistry Research Centre, University of Trás-os-Montes and Alto Douro, School of Life Science and Environment, Biology \\ and Environment Department, Edifício de Enologia, 5001-801 Vila Real, Portugal
}

\begin{abstract}
The main object of the present study was to investigate the volatile composition and sensorial profile of vine leaves infusions prepared from vine leaves collected 30 and 60 days after grape harvest from two Portuguese red grape varieties (Touriga Nacional and Tinta Roriz). Twelve volatile compounds were detected in vine leaves infusions (6-methyl-5-hepten-2-one, 1-undecene, Z-citral, cedrenol, DL-limonene, 2,4-hexadien-2-ol, benzaldehyde, heptane-1,2,4,6-tetraene, cyclohexene 1-methyl-4-(1-methylethyl), 1,6-octadien-3-ol, 3,7-dimethyl, 5,9-undecadien-2-one-6,10-dimethyl-(5E) and $\alpha$-cedrol). In addition, it was observed that the volatile compounds present in vine leaves infusions were dependent on the harvest time, with significantly major volatile content in vine leaves collected after 30 days of harvesting. Thus, it was more important the harvesting date for the volatile profile of vine leaves infusion than the vine leave grape cultivar. Similar tendency was also obtained for the sensory profile, with significant differences for astringency and aroma intensity attributes of vine leaves infusions according to the harvesting date.
\end{abstract}

\section{Introduction}

Vine leaves infusions may be a potential alternative not fully exploited for valorization of vine leaves after grape harvest that are often left on the vine itself or used as organic material for fertilization, animal feed or energy production. Vine leaves production, commercialization, and quality assessment (including sensory and volatile properties of vine leaves infusions) are not so developed as for wine and table grapes. Efficient discrimination tools can aid producers in optimizing and control the production process, namely harvesting time concerning to the leaves infusion quality. Although several authors have reported diverse biological properties of Vitis vinifera L. skins [1], seeds [2] and leaves [3,4], the volatile composition and sensory profile, especially from grapevine leaf infusions is particularly scarce. In addition, it is also particularly scarce the knowledge about the potential influence of vine leaves harvest date on the qualitative characteristics of the respective infusions obtained.

The potential use of vine leaves as herbal infusions is dependent on their composition and sensory characteristics. These properties are depending, namely on the volatile composition of the vine leaves used and the extraction process of these volatile compounds during the infusion preparation.

Thus, the main object of the present study was to investigate the volatile composition and sensory profile of

\footnotetext{
a e-mail: antoniojordao@esav.ipv.pt
}

vine leaves infusion prepared from vine leaves collected at two different points after grape harvest from two Vitis vinifera Portuguese red grape varieties.

\section{Material and methods}

\subsection{Vine leaves infusion samples}

Vine leaves, from two Portuguese red vine varieties (Vitis vinifera), Touriga Nacional and Tinta Roriz, were sampled 30 and 60 days after grapes harvest from 8-year-old grapevines in an experimental vineyard of northeastern Portugal.

Leaves were inspected visually before sampling and only intact and healthy leaves were sampled. Visual appearance of vine leaves in vineyard 30 and 60 days after grape harvest is show in Fig. 1. Samples of 40 leaves were picked randomly from 20 different vine plants from each vine variety. All vine leaves samples were dried until $10 \%$ of humidity in the dark and then they were crushed and homogenized and then kept in a dry atmosphere until analysis.

In order to reproduce extraction conditions that are similar to those in the infusions, vine leaves samples were placed in $500 \mathrm{~mL}$ of water at a concentration of $5 \mathrm{~g} / \mathrm{L}$ until the boil is achieved. At the end of this process and after 10 minutes, vine leaves infusions were filtered prior to the volatile analysis and also before the sensory evaluation. All essays were done in duplicate. 

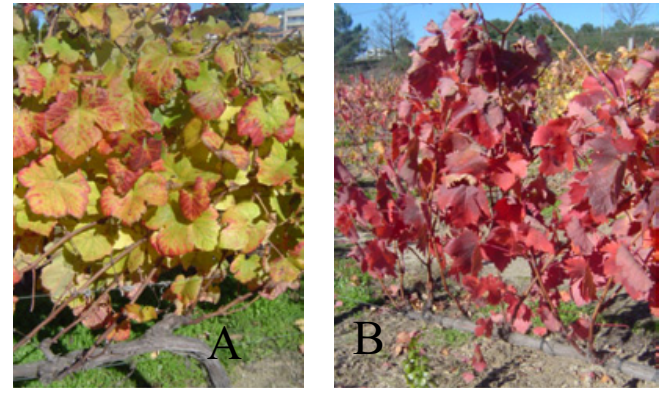

Figure 1. Visual appearance of vine leaves collected 30 (A) and 60 (B) days after grape harvest.

\subsection{SPME-GC-MS methodology}

For volatile characterization, a pre-conditioned (1 hour at $\left.300^{\circ} \mathrm{C}\right)$ SPME fiber $(75 \mu \mathrm{m}$ carboxen-polydithylosiloxane) was exposed to the headspace of the vine infusion sample during 30 minutes. Following adsorption process, the fiber was immediately inserted in the gas chromatography (GC) injection port. The samples analysis was performed with a trace GC ultra gas chromatograph (Thermo Finningan), equipped with a DB-1 $(0.50 \mu \mathrm{m} \times 0.25 \mathrm{~mm})$ fused silica column. GC conditions used were: programmed heating from $40^{\circ} \mathrm{C}$ during $4 \mathrm{~min}$ and heating to $220^{\circ} \mathrm{C}$ at $2.5^{\circ} \mathrm{C} / \mathrm{min}$, and $10^{\circ} \mathrm{C} / \mathrm{min}$ to $280^{\circ} \mathrm{C}$ during $5 \mathrm{~min}$. The injector was maintained at $280^{\circ} \mathrm{C}$. Helium was the carrier gas at $1.0 \mathrm{~mL} / \mathrm{min}$. The injection was made in the split less mode.

The GC was fitted with an ion trap mass spectrometer (MS), model Polaris Q (Thermo Finningan), using the following the MS conditions: ionization energy $70 \mathrm{eV}$, electronic impact ion source temperature $220^{\circ} \mathrm{C}$, scan mode: full scan, scan event time $0.69 \mathrm{~s}$, mass range 30-800 amu; the MS was operated in positive ion mode. The identification of the compounds were performed by comparing to those published in the literature [5] and comparing the mass spectra to those of the Wiley 6 mass spectra library. All analyses were done in duplicate.

\subsection{Sensory evaluation}

All vine leaves infusions were performed in a sensory analysis room with individual booths for each expert and according to standardized procedures. All evaluations were conducted in the afternoon (between 16:00 and 17:00) by sixteen expert judges with experience in sensory evaluation of leaves infusions. Vine leaves infusions samples were presented to the panel in white tea cups marked with three digit numbers and in a randomized order. The sensory attributes used were the following: visual (color intensity and hue), aroma (intensity), taste (astringency, bitterness and sweetness) and global appreciation. The judges were asked to evaluate the samples on a 1-10 quality point scale ( 1 being less intense and 10 more intense) for each attribute.

\subsection{Statistical analysis}

An analysis of variance and comparison of treatment means (ANOVA, one-way) were carried out using the SPSS software version 23.0 (Chicago, Illinois, USA). Differences between means were tested using Duncan test $(p<0.05)$. Principal component analysis (PCA) was used
A
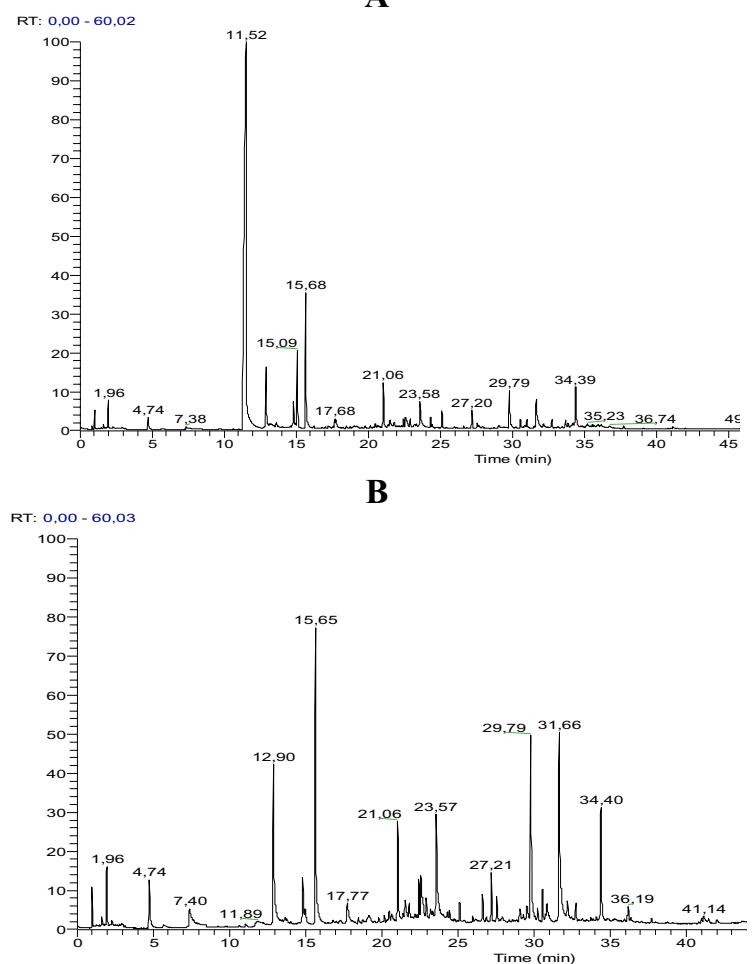

Figure 2. Chromatographic profiles found in vine leaves infusions obtained from Touriga Nacional leaves collected 30 (A) and 60 (B) days after grape harvest.

to analyze the relations between sensory characteristics of different vine leaves infusions from the two red grape varieties studied and also collected at two different harvest time.

\section{Results and discussion}

\subsection{Volatile composition of vine leaves infusions}

Figure 2 shows an example of a GC chromatographic profile obtained in vine leaves infusions acquired from vine leaves collected 30 and 60 days after grape harvest. By the analysis of Fig. 2, it is clear that it was possible to detect a higher number of different volatile compounds in the infusions prepared from vine leaves collected 60 days after grape harvested than in infusions prepared from vine leaves collected 30 days after grape harvest.

The individual volatile composition of vine leave infusions obtained from two different Portuguese red grape varieties (Touriga Nacional and Tinta Roriz) and harvested after 30 and 60 days of the grape harvest is shows in Table 1. Twelve different compounds were identified in vine leaves infusions.

For the infusions obtained from Touriga Nacional vine leaves collected 30 days after grape harvest a higher abundance of volatiles (total average peak area of $943.2 \times 10^{5}$ ) in comparison with that prepared from Tinta Roriz (total average peak area of $\left.597.7 \times 10^{5}\right)$ collected at the same harvest time was detected (Table 1). However, they were not significantly different for the leaves collected 60 days after grape harvest, where it was observed a similar total area (total average peak area of $225.2 \times 10^{5}$ and $211.5 \times$ $10^{5}$ for Touriga Nacional and Tinta Roriz, respectively). 
Table 1. Average peak area $\left(\times 10^{5}\right)$ and standard deviation of volatile compounds determined by SPME-GC-MS from vine leaves infusion of Touriga Nacional and Tinta Roriz leaves collected in two different dates.

Vine leaves infusions

\begin{tabular}{|c|c|c|c|c|}
\hline \multirow{2}{*}{ Compounds (sensorial attributes) } & \multicolumn{2}{|c|}{ Touriga Nacional } & \multicolumn{2}{|c|}{ Tinta Roriz } \\
\hline & $30 \mathrm{~d}^{(1)}$ & $60 \mathrm{~d}^{(\mathrm{II})}$ & $30 \mathrm{~d}$ & $60 \mathrm{~d}$ \\
\hline Heptane-1,2,4,6-tetraene & nd & $\begin{array}{c}15.4 \mathrm{a} \pm 1.5 \\
(6.8 \%)\end{array}$ & $\begin{array}{c}12.8 \mathrm{a} \pm 8.7 \\
(2.1 \%)\end{array}$ & $\begin{array}{c}14.9 \mathrm{a} \pm 0.05 \\
(7.0 \%)\end{array}$ \\
\hline 6-Methyl-5-hepten-2-one (wood, currant) & $\begin{array}{c}45.1 \mathrm{~b} \pm 1.0 \\
(4.7 \%)^{(\mathrm{III})}\end{array}$ & $\begin{array}{c}35.9 \mathrm{ab} \pm 3.5 \\
(16 \%)\end{array}$ & $\begin{array}{l}44.0 \mathrm{ab} \pm 0.3 \\
\quad(7.4 \%)\end{array}$ & $\begin{array}{c}35.4 \mathrm{ab} \pm 0.2 \\
\quad(17 \%)\end{array}$ \\
\hline 1,6-Octadien-3-ol,3,7-Dimethyl (mushroom) & $\begin{array}{c}105.9 \mathrm{a}+39.2 \\
(11 \%)\end{array}$ & $\begin{array}{c}62.8 \mathrm{~b} \pm 0.1 \\
\quad(28 \%)\end{array}$ & $\begin{array}{c}47.8 \mathrm{~b} \pm 0.2 \\
\quad(8.0 \%)\end{array}$ & $\begin{array}{c}48.5 \mathrm{~b} \pm 4.3 \\
(23 \%)\end{array}$ \\
\hline 1-Undecene (burnt) & nd & $\begin{array}{c}1.0 \mathrm{a} \pm 0.1 \\
(0.4 \%)\end{array}$ & $\begin{array}{c}18.7 \mathrm{~b} \pm 1.3 \\
\quad(3.1 \%)\end{array}$ & $\begin{array}{c}11.6 \mathrm{a} \pm 0.7 \\
(5.5 \%)\end{array}$ \\
\hline Z-Citral (lemon) & nd & $\begin{array}{c}24.8 \mathrm{ab} \pm 8.2 \\
(11 \%)\end{array}$ & nd & $\begin{array}{c}35.5 \mathrm{~b} \pm 1.0 \\
(17 \%)\end{array}$ \\
\hline 5,9 -Undecadien-2-one-6,10-dimethyl-(5E) & $\begin{array}{c}32.6 \mathrm{a} \pm 9.6 \\
(3.5 \%)\end{array}$ & $\begin{array}{c}39.6 \mathrm{a} \pm 0.1 \\
(18 \%)\end{array}$ & $\begin{array}{c}36.4 \mathrm{a} \pm 0.03 \\
(6.1 \%)\end{array}$ & $\begin{array}{c}28.7 \mathrm{a} \pm 0.5 \\
(14 \%)\end{array}$ \\
\hline Cyclohexene, 1-methyl-4-(1-methylethyl) & nd & nd & $\begin{array}{c}5.3 \mathrm{a} \pm 0.04 \\
(0.9 \%)\end{array}$ & $\begin{array}{c}31.1 \mathrm{~b} \pm 0.5 \\
(15 \%)\end{array}$ \\
\hline Cedrenol (cedar wood) & $\begin{array}{c}42.2 \mathrm{~d} \pm 3.9 \\
(4.5 \%)\end{array}$ & $\begin{array}{c}45.8 \mathrm{~d} \pm 5.8 \\
(20 \%)\end{array}$ & nd & $\begin{array}{c}5.8 \mathrm{ab} \pm 1.2 \\
(2.7 \%)\end{array}$ \\
\hline DL-Limonene (citrus) & $\begin{array}{c}33.6 \mathrm{a} \pm 3.7 \\
(3.6 \%)\end{array}$ & nd & nd & nd \\
\hline 2,4-Hexadien-2-ol (geranium, leaves) & nd & nd & $\begin{array}{c}7.7 \mathrm{~b} \pm 0.06 \\
(1.3 \%)\end{array}$ & nd \\
\hline$\alpha$-Cedrol (amphora) & nd & nd & $\begin{array}{c}10.7 \pm 3.1 \\
(1.8 \%)\end{array}$ & nd \\
\hline Benzaldehyde (almond) & $\begin{array}{c}683.9 \mathrm{~b} \pm 19.8 \\
(73 \%)\end{array}$ & nd & $\begin{array}{c}414.4 \mathrm{ab} \pm 50.6 \\
(69 \%)\end{array}$ & nd \\
\hline Total average peak area & 943.2b & 225.2a & $597.7 \mathrm{c}$ & 211.5a \\
\hline
\end{tabular}

Concerning to the individual compounds, the main individual volatile compound present in vine leaves infusions was benzaldehyde (aromatic notes of almond) being responsible for $69 \%$ and $73 \%$ of the total chromatographic area for Tinta Roriz and Touriga Nacional, respectively collected after 30 days of grape harvesting. However, benzaldehyde was absent in both vine leaves infusions for the leaves harvested 60 days after grape harvest. Opposite tendency was found for z-citral (aromatic note of lemon) that was quantified only in infusions prepared from vine leaves harvested at 60 days in both red grape varieties. This result support that the headspace composition of the vine leaves infusion was different between the two harvesting dates. Previously Weingart et al. [5] by the application of principal component analysis scores plot of vine leaves samples from two different sampling dates obtained two clearly separated clusters.

In addition, only three volatile compounds were quantified in all infusions independently of harvest date and vine variety (6-methyl-5-hepten-2-one, 1,6-octadien-3-ol, 3,7-dimethyl and 5,9-undecadien-2-one-6,10-dimethyl(5E)). DL-limonene (aromatic note of citrus) was only quantified in infusions prepared from Touriga Nacional leaves harvested at 30 days, while 2,4-hexadien-2-ol (aromatic notes of geranium and leaves) and $\alpha$-cedrol (aromatic note of amphora) were only quantified in infusions prepared from Tinta Roriz leaves harvested at 30 days.

\subsection{Sensory profile of vine leaves infusions}

Sensory profile for visual, aroma and taste descriptors of the different vine leaves infusions was evaluated and is shown in Fig. 3. The significantly differences were related to the astringency taste and aroma intensity attributes. Thus, the significantly highest astringency taste was obtained for the vine leaves infusions obtained from leaves collected 60 days after grape harvest, independently of the red grape variety studied. Similar tendency was obtained for aroma intensity, where vine leaves infusions from leaves collected 60 days after grape harvest showed the 

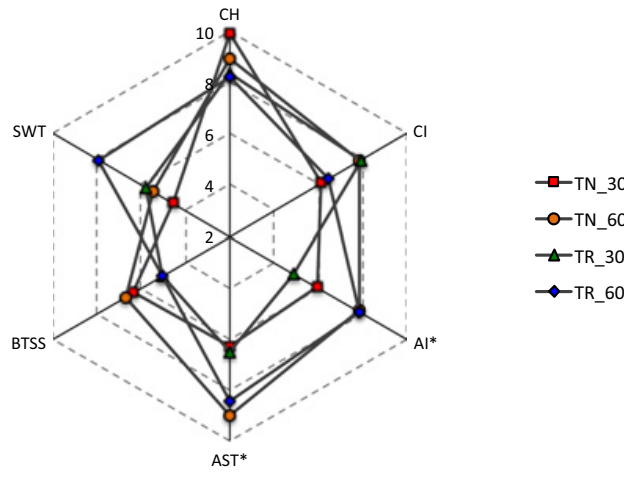

Figure 3. Sensory profile of vine leaves infusions obtained from Touriga Nacional and Tinta Roriz leaves collected 30 and 60 days after grape harvest.

$\mathrm{CH}=$ color hue; $\mathrm{CI}=$ color intensity; $\mathrm{AI}=$ aroma intensity; $\mathrm{AST}=$ astringency; BTSS $=$ bitterness; SWT $=$ sweetness. TN_30 $=$ Touriga Nacional infusion from leaves collected 30 days after grape harvest; TN_60 = Touriga Nacional infusion from leaves collected 60 days after grape harvest; TR_30 = Tinta Roriz infusion from leaves collected 30 days after grape harvest; TR_60 = Tinta Roriz infusion from leaves collected 60 days after grape harvest. (*) indicates the existence of statistical differences $(p<0.05)$ by Ducan Test.

highest scores for both red grape varieties used. These differences suggest that sensory profile, in particular some taste and aroma attributes, could be determined by the harvest date of vine leaves. For bitterness and sweetness taste and color hue and intensity visual attributes, panel test didn't detect significantly differences between the vine leaves infusions. However, for sweetness taste attribute, there was a slight differentiation (without statistical significance) between the vine leaves infusions obtained from Tinta Roriz leaves collected 60 days after grape harvest in relation to the other vine leaves infusions. Finally, for global appreciation scores (data not show) panel test didn't show significantly differences between the vine leaves infusions.

To get a deeper insight into the relationship between vine grape varieties, sample vine leaves date and their sensory characteristics, a principal component analysis (PCA) was performed on the sensory characteristics of vine leaves infusions (Fig. 4).

The first two principal components (PCs) explained $80.4 \%$ of the total variance observed in the original variables. Figure $4 \mathrm{~A}$ shows that the first PC (PC1, 51.8\% of the variance), was positively correlated with the variables, sweetness taste and global appreciation, and negatively correlated with the variables, color hue and bitterness taste, while the second PC (PC2, 28.6\% of the variance) was positively correlated with the variables, color hue and astringency taste.

In Fig. 4B it is possible to visualize the spatial distribution of the samples evaluated concerning to the sensory parameters analyzed. Thus, after a cluster analysis, one group is formed by the infusions obtained from vine leaves collected 60 days after grape harvest; these infusions are positioned in the positive side of PC1 and were independently of the red grape variety studied. In addition, the infusions obtained from vine leaves collected 30 days after grape harvest from Touriga Nacional and Tinta Roriz are positioned in second and forth quadrant, respectively.

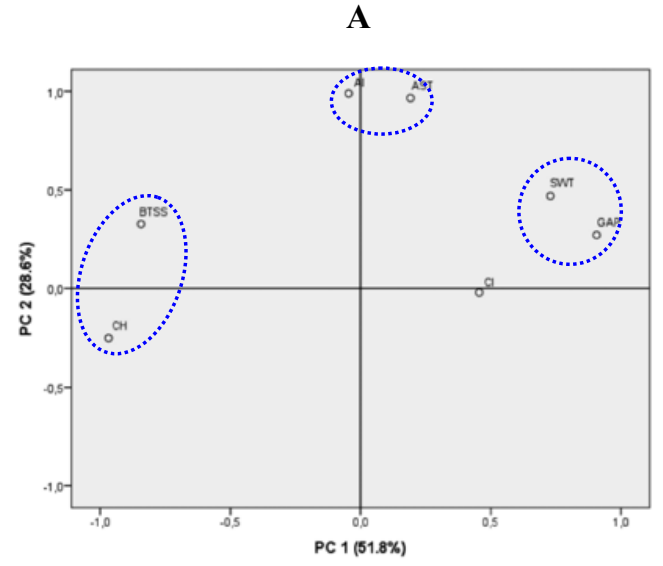

B

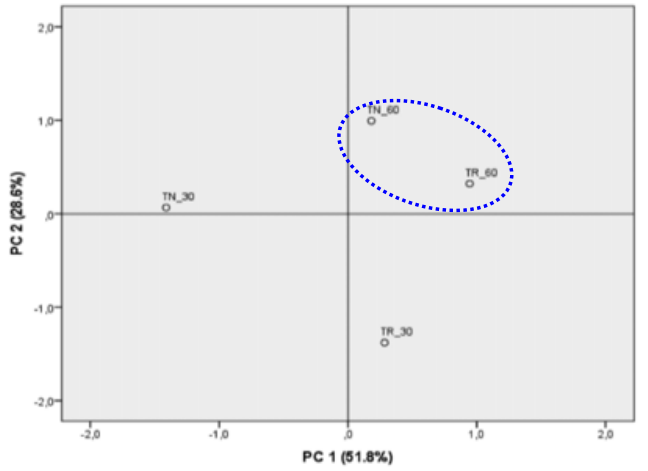

Figure 4. Projection of principal component analysis data from the sensory characteristics of vine leaves infusion samples analyzed: loading plots (A) and scores-plot (B).

$\mathrm{CH}=$ color hue; $\mathrm{CI}=$ color intensity; $\mathrm{AI}=$ aroma intensity; AST $=$ astringency $;$ BTSS $=$ bitterness; SWT $=$ sweetness; GAP $=$ global appreciation TN_30 = Touriga Nacional infusion from leaves collected 30 days after grape harvest; TN_60 = Touriga Nacional infusion from leaves collected 60 days after grape harvest; TR_30 = Tinta Roriz infusion from leaves collected 30 days after grape harvest; TR_60 = Tinta Roriz infusion from leaves collected 60 days after grape harvest.

\section{Conclusions}

In this work, it was possible to detect a tendency for a more clear influence of the harvesting date on the volatile composition and sensory profile of vine leaves infusions than the vine leave grape variety. Regarding to specifically for the volatile composition, the highest values quantified in vine leaves infusions from leaves collected 30 days after grape harvest were determined namely by the highest content of benzaldehyde. In addition, it was also clear that infusions from leaves collected 60 days after grape harvest showed the highest sensory scores for both red grape varieties used, in particular for aroma intensity and astringency taste.

These results could be important to contribute the better harvest time to collects vine leaves for infusion production. However further research, including more detailed chemical analysis (especially by the analysis of other group of compounds, such as phenolic compounds), more samples points after grape harvest and using other grape varieties it will be necessary to improve the knowledge about the quality of grape vine leaves for infusion production. 
Authors thanks to FCT (projects UID/Multi/04016/2016 and PEst-OE/QUI/UI0616/2014), Chemistry Research Centre in Vila Real (CQ-VR) and IPV-CI\&DETS in Viseu for their financial support.

\section{References}

[1] A. El-Din, A. Bekhit, V.J. Cheng, M. McConnell, J.H. Zhao, R. Sedcole, R. Harrison, Food Chem. 129, 837 (2011)
[2] G.K. Jayaprakasha, T. Selvi, K.K. Sakariah, Food Res. Int. 36, 117 (2003)

[3] F. Fernandes, E. Ramalhosa, P. Pires, J. Verdial, P. Valentão, P. Andrade, A. Bento, Ind. Crops Prod. 43, 434 (2013)

[4] N. Ceyhan, D. Keskin, Z. Zorlu, A. Ugur, J. Pure Appl. Microbio. 6, 1303 (2012)

[5] G. Weingart, B. Kluger, A. Forneck, R. Krska, R. Schuhmacher, Phytochem. Anal. 23, 345 (2012) 